\title{
Gestão pública orientada para resultados no Brasil $^{1}$
}

\author{
Ariel Garces e José Paulo Silveira
}

\section{Introdução}

O Plano Plurianual (PPA 2000-2003), denominado Avança Brasil, trouxe mudanças de impacto no sistema de planejamento e orçamento federais, assim como na gestão pública. Com a recuperação da estabilidade da moeda e o processo de ajuste fiscal, iniciado em 1994, com o Plano Real, formou-se o entendimento de que se impunha um choque gerencial na administração pública brasileira. A decisão foi transformar o plano em instrumento de gestão, orientando a administração pública para resultados.

O Decreto no 2.829 , de outubro de 1998 , constituiu a base legal para a reestruturação de todas as ações finalísticas do governo. Esse decreto determina que o programa seja a forma básica de integração entre plano e orçamentos, fixa os princípios de gerenciamento dos programas e do plano, cria a figura do gerente de programa, fixa suas principais responsabilidades e cria a obrigação de avaliação anual de desempenho de todos os programas e do plano.

Após dois anos e meio de implantação desse novo modelo de gestão, é possível contabilizar mudanças importantes e definitivas na administração pública brasileira, tantas quantos são ainda os desafios para a consolidação de uma gestão pública empreendedora. Por isso pareceu uma contribuição útil mostrar os aspectos estruturais desse modelo, terminando por mencionar os principais desafios que a experiência, apesar de curta, mostra claramente. 


\section{O equilíbrio fiscal a a reforma do Estado}

A experiência brasileira de implantar e manter uma política de equilíbrio fiscal tem mostrado, nos últimos oitos anos (1994-2002), as restrições que essa iniciativa impõe à implementação das políticas públicas relacionadas ao desenvolvimento, caso estas não venham associadas a medidas de otimização do gasto. A harmonia entre a condução das políticas de regulação macroeconômica e as demais políticas setoriais tem se transformado em um dos principais desafios do atual governo. A opção foi adotar o PPA 2000-2003 como projeto de desenvolvimento e, ao mesmo tempo, instrumento de racionalização e melhoria da qualidade do gasto, levando em conta um cenário de restrições ao seu financiamento.

Para compreender melhor essas mudanças, é importante lembrar que a estabilização econômica e a política de equilíbrio fiscal, no Brasil, fizeram com que as taxas de inflação, medida pelo Índice Nacional de Preços ao Consumidor (INPC), caíssem de 5.014\%, nos 12 meses que antecederam o Plano Real, para 22\% nos 12 meses seguintes (1995), 9\% em 1996, 4\% em 1997, 2,5\% em 1998, voltando a subir para 8,4\% em 1999, ano da desvalorização e da implementação da política de câmbio flutuante, retornando para 5,3\% em 2001. Os números, contudo, não mostram a magnitude da redução do gasto público que a estabilização impôs. O país se acostumara, após décadas de inflação, a ampliar artificialmente as despesas, financiando as demandas sociais e de infra-estrutura crescentes com o chamado imposto inflacionário.

Em 1996, um ano após a estabilização, o governo lançou o Plano Diretor da Reforma do Aparelho do Estado, cuja finalidade era a reestruturação das organizações, para atribuir-lhes flexibilidade administrativa e responsabilização.

Em 1998, a crise da Rússia ampliou as repercussões negativas da restrição fiscal, de tal modo que, ao lado da reestruturação das organizações, prevista pelo Plano Diretor, foram adotadas duas outras importantes iniciativas no âmbito da reforma do Estado, voltadas para os instrumentos de gestão. A primeira, a Lei de Responsabilidade Fiscal (LRF) (Lei Complementar no 200), permite um planejamento fiscal, de médio prazo, importante para a orientação do gasto futuro, elemento indispensável à credibilidade do plano. A segunda, o PPA 2000-2003, está progressivamente introduzindo alterações profundas na programação de recursos e no ciclo de gestão do setor público brasileiro: o plano, o orçamento, a execução orçamentária e financeira e a avaliação de desempenho da ação governamental. São, todas as duas, iniciativas que atingem o coração dos instrumentos de equilíbrio fiscal e, ao mesmo tempo, de alocação e aplicação de recursos. 
As inovações gerenciais, introduzidas pelo PPA 2000-2003, decorrem da evolução de uma experiência-piloto de gerenciamento, executada entre 1996 e 1999. Ainda, no primeiro mandato do presidente Fernando Henrique Cardoso, foi criado o Programa Brasil em Ação, com a finalidade de administrar um conjunto de 42 empreendimentos estratégicos, distribuídos nas áreas social e de infra-estrutura, no valor total de US\$ 28 bilhões, dos quais apenas 16,5\% eram recursos do orçamento da União. Pela primeira vez, foram empregados os gerentes de empreendimento, o sistema de informações gerenciais, o controle de fluxo financeiro e a gestão de restrições. O êxito dessa experiência foi determinante para que o governo tomasse a decisão de adotar esses princípios para todas as ações do Governo Federal.

\section{Integração plano, orçamento e gestão}

O novo modelo de planejamento baseia-se na integração dos instrumentos de planejamento, orçamento e gestão, organizados segundo três horizontes de tempo: oito anos; quatro anos e um ano.

O primeiro horizonte de planejamento adotado oferece uma visão estratégica do desenvolvimento a longo prazo, referenciado ao território, para os próximos 20 anos. Trata-se de uma visão de futuro orientada também para resultados concretos, por isso se traduz em portfolio de investimentos necessários ao crescimento equilibrado e integrado de todas as regiões do país para os próximos oito anos. Com essa idéia, cria-se o conceito de planejamento indicativo para as várias esferas do setor público, como também subsidia as decisões microeconômicas de investimento do setor privado, das agências de financiamento e das entidades do terceiro setor.

Para definir o portfolio de investimentos para o horizonte de oito anos, foi realizado amplo estudo, denominado Eixos Nacionais de Integração e Desenvolvimento 2000-2007. O estudo é uma radiografia dos grandes problemas nacionais e das imensas oportunidades que o país oferece. Ao varrer o território nacional, levantar as realidades regionais e identificar potencialidades e obstáculos ao crescimento, o estudo tornou possível compreender melhor o país e definir caminhos para o desenvolvimento econômico e social. O portfolio identificou investimentos, envolvendo US\$ 228 bilhões entre recursos públicos e privados, distribuídos em $6 \%$ na área de meio ambiente, $1 \%$ em informação e conhecimento, $49 \%$ em desenvolvimento social e $44 \%$ em infra-estrutura econômica. O estudo partiu de premissas relativamente novas nos debates sobre desenvolvimento regional. Adotou um enfoque geoeconômico no lugar do enfoque geopolítico, no sentido de privilegiar os aspectos de complementaridade entre as regiões e, sobretudo, valorizar uma nova forma de perceber o que é estratégico 
para cada região, muitas vezes estando este localizado em outra região. A percepção do que é essencial para cada Estado ganhou novas perspectivas com a criação de uma nova unidade de programação, denominada Eixos de Integração e Desenvolvimento. Ao todo foram identificados nove eixos, cujos espaços passaram a ser uma referência para os investimentos públicos e privados.

Concluído o relatório preliminar do estudo, iniciou-se a discussão do portfolio de investimentos em fóruns qualificados. Foram realizadas reuniões de trabalho nos ministérios para validar as conclusões do estudo. Foram ainda realizadas 27 reuniões, uma em cada Estado da Federação. A experiência de discussão contribuiu para melhorar a qualidade dos resultados do estudo e aumentar o nível de adesão à estratégia de desenvolvimento do país.

A perspectiva dos Eixos Nacionais de Integração e Desenvolvimento não só balizou a organização espacial dos programas do plano, como permitiu selecionar os empreendimentos estruturantes que aportam no PPA 2000-2003 a dimensão de um projeto de desenvolvimento nacional.

O PPA é uma lei e torna-se, portanto, um plano normativo para todo o setor público federal, no horizonte de quatro anos. O PPA 20002003, pela primeira vez, organizou todas as ações em 365 programas, referência para a formulação dos orçamentos anuais. Estes foram criados como um desdobramento operacional das Orientações Estratégicas do Presidente, com macroobjetivos formulados a partir do estudo dos Eixos Nacionais de Integração e Desenvolvimento e da proposta de governo do presidente eleito. Os recursos foram alocados aos programas a partir de uma modelagem consistente do ponto de vista do equilíbrio fiscal.

Com esses dois primeiros horizontes de planejamento, os orçamentos anuais passam a ser conseqüência da visão estratégica plurianual, assegurada pelos programas que integram, simultaneamente, o plano e os orçamentos anuais.

Assim, há a possibilidade de superar a tendência natural à extrapolação plurianual do gasto, tradicional na cultura orçamentária e financeira. O programa passa a ser, nesse novo modelo de planejamento e orçamentação, o elemento de ligação entre o futuro desejado e programado nos dois horizontes, de quatro e oito anos, e as decisões de curto prazo da programação orçamentária e financeira.

\section{O programa}

O programa é um conjunto articulado de ações (relativas a investimentos, despesas correntes e outras ações não orçamentárias), para o alcance de um objetivo. Esse objetivo é concretizado em resultados - 
resultado é a solução de um problema ou o atendimento de demanda da sociedade - mensurados pela evolução de indicadores no período de execução do programa, possibilitando, assim, a avaliação objetiva da atuação do governo.

\section{Programa como unidade de gestão pública}

A constituição dos programas pressupõe orientar toda a ação do governo para a resolução de problemas ou demandas da sociedade. Isso rompe com a visão departamentalizada das organizações do setor público, cuja tradição tem sido a de otimizar sua função, independente dos resultados globais atingidos. A intenção é introduzir paulatinamente, nas organizações públicas, uma preocupação gerencial com objetivos a serem atingidos na sociedade.

A construção de programas a partir das demandas da sociedade leva também à formulação de programas multissetoriais mais eficazes do que a programação setorial, típica das organizações departamentalizadas do setor público. Há, assim, uma possibilidade crescente de que a administração pública possa auscultar a sociedade, atender o cidadão e ter neste o seu referencial para a gestão.

\section{Programa como viabilizador de parcerias internas e externas}

A outra face, menos conhecida, do conceito de programa está nas possibilidades que este abre para a conjugação de recursos e a racionalização do gasto mediante a incorporação de parcerias, que se formalizam nos instrumentos de gestão do governo. O programa organiza as parcerias tanto internas quanto externas ao governo.

As mudanças decorrentes do novo papel do Estado abrem oportunidades de combinar ações públicas e privadas para objetivos de administração pública. Assim, os programas criados pelo PPA 2000-2003, além de definirem as ações financiadas com recursos fiscais, da seguridade social e das empresas estatais, todos subordinados aos imperativos do equilíbrio fiscal, trazem incorporados também as parcerias externas, os recursos da iniciativa privada, do terceiro setor e das unidades subnacionais, Estados e municípios. A experiência brasileira tem mostrado o êxito das parcerias tanto nas áreas de infra-estrutura como nas de desenvolvimento social.

Dois exemplos podem ser mencionados: os programas voltados para a redução da mortalidade infantil, que conseguiram, graças à ação conjunta de organizações não-governamentais, governo central e local, uma redução de 41 em cada 1.000 nascidos, em 1995, para 28 em cada 1.000 nascidos, 
em 2001; a construção da ferrovia que liga as regiões produtoras de grãos, no Centro-Oeste do país, com o porto de Santos, no Estado de São Paulo (Ferronorte), investimento privado que se tornou viável em função da combinação de ações públicas e privadas.

O fato de os programas terem sido desenhados a partir da demanda da sociedade deu origem, naturalmente, aos programas multissetoriais. Estes são a conjugação de ações de diferentes órgãos da administração, articulados por um programa cuja gestão está confiada a um único ministério e a um só gerente. A ação governamental ganha a possibilidade de equacionar problemas da sociedade com o mínimo de recursos, desde que sejam rompidas as barreiras corporativas da administração tradicional.

\section{Programa como referência para alocação de todos os recursos}

Todos os recursos do orçamento são alocados aos programas que estão previstos no PPA, na forma de ações orçamentárias, à exceção das transferências constitucionais devidas aos Estados e municípios e do pagamento de dívidas do Governo Federal. Os programas, contudo, são mais amplos e completos e integram também outras ações, denominadas de "ações não orçamentárias", que expressam outras fontes de recursos do governo para financiar o cumprimento da sua missão.

No caso de investimentos (despesas de capital), pode-se afirmar que há mais recursos sendo aplicados, anualmente, fora do orçamento do que os investimentos alocados por este último. Desse modo, o programa passa a ser não só uma unidade para a alocação dos recursos de natureza fiscal, mas incorpora também os recursos disponíveis das agências oficiais de crédito, dos incentivos fiscais, dos fundos constitucionais de financiamento às regiões mais pobres, dos fundos administrados pelo Governo Federal, cujos recursos pertencem à sociedade, e dos dispêndios correntes das empresas estatais (não orçamentários pela legislação brasileira).

O programa foi concebido para integrar um conceito amplo de recursos. Não se limita apenas ao financeiro. A intenção desse programa é prover o governo de um mapa, os programas, que norteie todos os meios da administração - recursos humanos, organizacionais, materiais e de conhecimento - para os fins definidos e possa orientar as decisões da alta direção da administração. A pouca experiência da burocracia em negociação e elaboração de acordos estratégicos entre as organizações que fazem parte de determinado programa tem sido um óbice para a aplicação completa desse conceito. Não se podem esquecer, igualmente, os prejuízos que traz a ausência, por um lado, de cobrança mais generalizada do desempenho das organizações e, por outro, de mecanismos para premiar o desempenho das equipes dos programas bem-sucedidos. 


\section{Gerenciamento}

O conceito de planejamento adotado pelo PPA 2000-2003 vai além da sua função clássica de formular planos. Incorpora, também, como essencial, o gerenciamento dos programas e do plano. O modelo gerencial adotado tem o objetivo de atribuir responsabilidades, orientar os esforços das equipes envolvidas na execução, para a obtenção de resultados, e, por último, assegurar a atualização permanente do plano. A forma encontrada para assegurar a qualidade do gerenciamento foi a de criar a figura do gerente de programa, o monitoramento em rede, com o apoio de um sistema de informações gerenciais, o gerenciamento intensivo dos programas estratégicos e a avaliação anual de desempenho de todos os programas e do plano.

\section{Gerente de programa}

O gerente de programa é o fator crítico de sucesso do modelo de planejamento, orçamento e gestão por programas. Para cada programa há um só gerente responsável, designado pelo ministro do ministério ao qual está afeto o programa.

Observa-se aqui o princípio da responsabilização clara pelo desempenho, custos e resultados.

As funções do gerente de programa, no modelo proposto, são:

- planejar a execução do programa;

- formar e motivar a equipe;

- negociar os compromissos com as parcerias externas e internas;

- manter um sistema de informações gerenciais para o controle do desempenho e da gestão de restrições;

- promover a execução das ações de forma a obter os resultados desejados;

- participar da administração orçamentária e financeira;

- comunicar-se com o público-alvo do programa; e

- avaliar e aperfeiçoar continuamente o programa.

O gerente é também o responsável pelo registro do desempenho físico das ações do programa. Com a institucionalização do Sistema de Informações Gerenciais e de Planejamento (Sigplan), o gerente é o responsável único pelo registro, para controle do governo, do resultado direto do gasto, a denominada meta anual por ação (e.g., número de crianças vacinadas, quilômetros de rodovia pavimentados, número de habitações construídas, número de parques nacionais mantidos).

Não havia na administração, até a criação do gerente de programa, um responsável pelo controle do ciclo produtivo do Estado, resultante dos recursos alocados no orçamento e efetivamente aplicados. 
A estratégia de implantação do modelo gerencial foi centrada no gradualismo e no processo adaptativo das organizações. Criou-se, no interior das organizações, uma tensão entre a gestão departamental e a gestão por objetivos.

Passados dois anos e meio, presenciam-se diversas situações de designação de funções aos gerentes, conforme a adoção do modelo, em cada ministério. De qualquer modo, o grau de internalização do modelo tem sido relativamente elevado no conjunto dos ministérios, muito mais por força de ação coordenada pelo Ministério do Planejamento, Orçamento e Gestão, de capacitação e valorização do gerente, bem como do envolvimento deste nos eventos do ciclo de gestão, do que pela subordinação dessas organizações a uma norma que lhes impusesse o novo modelo gerencial. O objetivo é promover uma assimilação dos novos valores gerenciais pelas equipes, pela alta direção dos ministérios e pelas organizações vinculadas.

\section{Monitoramento em rede}

O novo modelo pressupõe um processo de monitoramento em rede, cujas bases são: o gerente, situado no ministério setorial; o monitor de programas, situado no Ministério do Planejamento, cujo trabalho é facilitar a resolução de restrições à execução dos programas; e o Sigplan, sistema informatizado que fornece ao gerente os meios necessários para controlar a execução do programa. Esse sistema ao mesmo tempo, articula em rede a alta direção do governo e o conjunto de gerentes e monitores.

O enfoque prospectivo é uma das características importantes do sistema, uma vez que possibilita aos gerentes a antecipação de restrições à execução do programa, o que facilita a mobilização e a busca de soluções por parte do governo e de seus parceiros. A esta atividade chama-se de gestão de restrições. Entende-se por restrição todo problema que pode impedir ou prejudicar a execução de uma ou mais ações do programa, cuja solução está além do alcance do gerente.

Outro aspecto importante é a existência de um módulo do sistema especificamente para a sociedade, que tem a finalidade de dar transparência às ações de governo.

O objetivo é apresentar à sociedade o andamento do plano, usando uma linguagem fácil e mostrando casos de impacto dos programas. Foi desenvolvido para isso uma página na Internet, que pode ser acessada por qualquer cidadão no endereço: www.abrasil.gov.br.

\section{Avaliação anual dos programas e do plano}

Prevista no Decreto no 2.829 e na lei do PPA 2000-2003, a avaliação de desempenho é uma das etapas mais importantes do ciclo de gestão do Governo Federal. Seu objetivo é assegurar o aperfeiçoamento 
contínuo dos programas e do plano, provendo subsídios para corrigir falhas de concepção e execução, atualizar objetivos e metas em relação às demandas da sociedade e garantir que os resultados desejados para o público-alvo ocorram efetivamente.

A avaliação está orientada para a obtenção de resultados e se realiza uma vez por ano, tendo como referência o exercício anterior. No ciclo de gestão, a avaliação é seguida da revisão anual dos programas, da elaboração da Lei de Diretrizes Orçamentárias e da elaboração e execução da Lei Orçamentária Anual. Os resultados da avaliação contribuem para a realização de cada uma dessas etapas, tornando mais consistente a alocação de recursos públicos federais aos bens e serviços demandados pela sociedade.

Nesse contexto, o processo de avaliação é um instrumento gerencial que se integra ao conjunto de ferramentas do novo modelo de gestão do Governo Federal.

Mais que controlar custos, assegurar a conformidade legal de procedimentos ou medir a capacidade de implementação do governo, avaliar significa, nesse caso, comparar o esforço realizado com a demanda e a satisfação do beneficiário, adequando crescentemente os programas à expectativa da sociedade. O processo de avaliação, realizado de forma participativa e transparente, proporciona, além disso, a ampliação do conhecimento dos gerentes e de suas equipes sobre o programa, fortalecendo a sua capacidade de promover e articular a obtenção de resultados.

Levando em conta esses propósitos, a metodologia para a avaliação dos programas valorizou principalmente a análise de resultados, tendo como elementos de referência os objetivos do programa, a variação observada em seus indicadores e o grau de satisfação do público-alvo, sempre que esses elementos puderam ser medidos ou apurados em tempo hábil. Em segunda aproximação, o foco da análise de resultado se dirige para o alcance das metas das ações, ou seja, o seu grau de execução física comparado ao desempenho alcançado na execução financeira.

As causas do bom ou mau desempenho são analisadas em dois blocos. O primeiro considera a contribuição da concepção do programa, trata de avaliar se os componentes do desenho do programa - seu objetivo, indicadores, ações, metas, produtos e serviços — são consistentes entre si e adequados para atender à demanda ou resolver o problema que lhe deu origem. No outro, discutem-se os mecanismos, os processos e as condições da execução, em relação aos resultados esperados. Na avaliação da execução, busca-se verificar a adequação e suficiência dos recursos alocados, a pertinência e eficácia da estratégia de implementação, assim como os reflexos do modelo gerencial e da estrutura organizacional sobre o desempenho do programa. 
Realizado inteiramente em ambiente informatizado, o processo de avaliação de programas constitui, por si só, eficiente instrumento de transformação e modernização da gestão governamental. Para garantir a qualidade dos resultados e a uniformidade de procedimentos, foi inicialmente elaborado o Manual de Avaliação de Programas, que descreve a metodologia adotada, as rotinas e os instrumentos de cada etapa do processo, assim como os órgãos e as pessoas responsáveis pela execução.

A avaliação é realizada em três etapas. Na primeira, o gerente, de comum acordo com sua equipe, responde a um questionário organizado em três blocos de assuntos: resultados obtidos, concepção do programa e execução.

Na segunda etapa, são mobilizados diversos escalões dos ministérios, sob a coordenação das respectivas áreas de planejamento e orçamento, para a tarefa de comparar os resultados dos programas com os objetivos estratégicos definidos pelo ministério para a sua atuação.

Na terceira etapa, técnicos do Ministério do Planejamento realizam avaliação do conjunto de programas em relação aos macroobjetivos do PPA, procedendo, também, à análise de consistência das avaliações realizadas pelos gerentes e órgãos setoriais e à elaboração da síntese das avaliações de cada programa. Além disso, são realizadas análises estatísticas, visando identificar as imperfeições do modelo, assim como restrições recorrentes ou sistêmicas à implementação dos programas, cuja superação possa resultar em aperfeiçoamento do plano ou de seu modelo de gestão.

Os resultados da avaliação são encaminhados ao Congresso Nacional em abril de cada ano e disponibilizados, em seguida, para o público em geral, por meio da Internet (www.abrasil.gov.br).

\section{Gestão estratégica}

O PPA 2000-2003, integrado com os orçamentos anuais, reflete um projeto de desenvolvimento para o país. Contudo, a experiência de planejamento estratégico mostra que tão importante quanto a definição de objetivos e prioridades é assegurar as condições para a gestão estratégica do plano. Assim, essa gestão inicia-se na alocação estratégica de recursos e estendese até o gerenciamento intensivo de programas considerados estratégicos.

\section{Definição de programas e ações estratégicas}

Uma etapa importante é a identificação de programas que permitam à administração federal alcançar os seus objetivos estratégicos. São programas que, pela sua natureza, pelo volume de recursos envolvidos ou pela sua relevância, são estruturadores do projeto de desenvolvimento. 
Atualmente, existem 67 programas estratégicos, de um total de 387 programas do plano, submetidos a um gerenciamento intensivo. Na área social, têm destaque os programas nas áreas de saúde, educação, previdência e assistência social, reforma agrária, segurança pública, redução da pobreza. Na área de infra-estrutura econômica, foram priorizados os empreendimentos de transporte e energia, com foco especial neste último setor, em função da crise de abastecimento de energia elétrica, desencadeada a partir de maio/junho de 2001. Em conseqüência, todos os programas na área de energia foram integrados ao conjunto de programas estratégicos.

\section{Alocação estratégica de recursos}

Um país em desenvolvimento, como o Brasil, não pode se dar o privilégio de elaborar um orçamento incremental. A alocação estratégica representa um ponto crítico no processo, diante da escassez de recursos e da disputa entre os ministérios para atender à demanda setorial. Ao mesmo tempo, existe a tendência de o setor público trabalhar de forma incrementalista, sem atentar para os objetivos estratégicos.

Assim, a alocação estratégica de recursos aos programas exige clareza de prioridades e esforço de negociação dentro do governo.

A alocação estratégica de recursos não é rígida. Uma vez por ano, por ocasião da elaboração do projeto de lei de diretrizes orçamentárias, a relação dos programas estratégicos é ajustada a uma análise da evolução do plano e das demandas da sociedade, considerando a disponibilidade de recursos. É nessa ocasião que é definido também o montante global de recursos alocados a esses programas.

\section{Gerenciamento intensivo dos programas estratégicos}

Para garantir que os programas e as ações estratégicos sejam efetivamente implementados, foi desenvolvido um sistema de gerenciamento intensivo, envolvendo os níveis operacionais e os altos escalões do governo. O sistema adotado segue os princípios básicos do modelo gerencial do PPA 2000-2003 e se apóia na rede de gerentes e no Sistema de Informações Gerenciais. Aqui, o diferencial é o controle do fluxo de recursos e a cooperação mais estreita para a superação de restrições.

A gestão do fluxo de recursos, realizada pela área de planejamento do Ministério do Planejamento, tem por objetivo assegurar os meios financeiros para a execução física das ações dos programas estratégicos. O controle envolve a participação dos gerentes e dos monitores de programas, além de uma equipe, com dedicação exclusiva, de apoio ao gerenciamento

dos programas estratégicos. Com base nas informações prestadas pelo 
gerente, é estabelecido um fluxo de caixa, projetado em função das necessidades de execução física para o mês corrente. Nesse processo, os responsáveis pelo monitoramento têm a função de verificar a execução orçamentária e a financeira relativas ao mês anterior e sua compatibilidade com a evolução física das ações, para orientar a tomada de decisão quanto ao volume de recursos a serem liberados pelo Tesouro Nacional.

Os programas estratégicos são submetidos a uma avaliação mensal, que informa o Relatório de Situação dos Programas Estratégicos, entregue mensalmente ao presidente da República.

Para permitir o acompanhamento, em tempo real, desses programas, foi implantada, na Presidência da República, uma Sala de Situação, equipada com os recursos tecnológicos necessários à informação do presidente da República.

\section{Desafios do modelo}

A reestruturação do planejamento governamental, a partir dos anos 90, com os planos plurianuais do Governo Federal de 1996-1999 e de 2000-2003, trouxe consigo o desafio de repensar a sua missão, os seus conceitos e procedimentos. O Estado e a sociedade que emergem nesse período são profundamente diferentes do planejamento, dos anos 70. Os avanços implementados nos últimos anos refletem o novo ambiente da gestão pública e, mais precisamente, a influência de três fatos marcantes, cujo exame ajuda a compreender melhor a envergadura das mudancas em curso, assim como mostra a direção dos novos passos, necessários à consolidação desse processo.

O primeiro refere-se à assimilação, pelo planejamento, dos novos princípios organizacionais e de gestão, que passaram a dominar o movimento de reestruturação do setor público no mundo e, também, no Brasil, com a reforma gerencial introduzida pela Reforma do Aparelho de Estado, em 1995. A noção de planejamento orientado para resultados e intensivo em gestão foi conseqüência natural desse processo contínuo de aperfeiçoamento da gestão pública, incorporando experiências do setor público de outros países, além de inovações decorrentes do aprendizado e da avaliação crítica dos modelos implementados. Nasce, assim, a idéia de combinar um planejamento abrangente que envolvesse o conjunto de bens e serviços prestados pelo Estado com uma gestão estratégica de um conjunto seletivo de programas considerados estratégicos. No primeiro caso, a definição de metas plurianuais de desempenho deveria elevar a capacidade sistêmica do Estado de gerar resultados crescentes. No segundo, a seletividade e a focalização da ação governamental deveria assegurar a obtenção das transformações essenciais à sociedade. 
O segundo diz respeito à importância de ampliar a missão do planejamento governamental, para que pudesse incorporar novos objetivos de gestão oriundos das mudanças no papel do Estado, que ocorrem nesse período. Trata-se, por exemplo, de manejar a visão estratégica e a transparência na alocação do gasto público, proporcionado pelo planejamento, para atrair os investimentos privados e a cooperação do terceiro setor na direção das demandas de desenvolvimento. Cria-se, assim, o conceito de planejamento indicativo para um horizonte de longo prazo, oito anos, o equivalente a dois planos plurianuais, e referenciado ao território. Em outra vertente, a necessidade de pensar a sustentabilidade fiscal a longo prazo cria as condições favoráveis para planejamento do gasto com âncora fiscal, tornando a integração plano/orçamentos um processo natural, em uma gestão pública orientada também pela disciplina fiscal. A LR Fiscal, sabiamente, lança mão da plurianualidade fiscal e da necessidade de vincular o gasto público ao seu impacto futuro, por meio dos anexos fiscais da Lei de Diretrizes Orçamentárias e do Plano Plurianual. Há uma forma nova de planejar o gasto público, que se impõe definitivamente, com largas consequiências futuras para a função planejamento. Como combinar desenvolvimento com disciplina fiscal? Essa nova tensão é que tem levado a incorporação de novos conceitos e práticas à função do planejamento. Um exemplo é a necessidade de manejar simultaneamente recursos fiscais e não fiscais, públicos e privados, ou de articular a cooperação entre o Estado, a comunidade e o terceiro setor, orientando esses conjuntos heterogêneos de meios para resultados e transformações na sociedade.

O terceiro responde à necessidade de incorporar a noção de desenvolvimento sustentável no âmbito da gestão pública. Transformado em conceito de valor público a partir dos anos 90, vêem-se, em todo o mundo, iniciativas de incorporar os princípios da Agenda 21 na missão do Estado contemporâneo e na forma de conceber o desenvolvimento. O planejamento referenciado ao território foi a opção encontrada. Assim, noções de ordenamento e desenvolvimento do território ganham um novo destaque. Há o reconhecimento simultâneo de que as regiões competem entre si e de que a visão de desenvolvimento integrado e equilibrado do território nacional é tão importante quanto assegurar a melhoria de desempenho de cada um dos múltiplos setores que ajudam a melhorar a qualidade de vida do cidadão que mora na região.

Em outras palavras, o desenvolvimento sustentável introduziu a necessidade de combinar planejamento setorial com planejamento territorial. Tornou mais abrangente o conceito tradicional de desenvolvimento regional, baseado na necessidade de atenção maior do setor público apenas sobre as regiões menos desenvolvidas ou estagnadas, e introduziu o conceito de desenvolvimento solidário de todos os territórios, baseado na competitividade da nação que este aporta do ponto de vista da sua inserção internacional. 
Introduziu ainda um acompanhamento do desenvolvimento diferenciado das regiões, subordinado à elevação da qualidade de vida local e da preservação dos recursos naturais.

Influenciado por essas forças que movem grande parte da reforma do Estado brasileiro, a experiência do PPA 2000-2003 introduziu um conjunto de inovações, que ainda permanece como desafios de processo de transformação mais profundo do planejamento governamental e da gestão pública. Um balanço desses anos mostra a importância, para a administração pública, de encarar essas mudanças em cinco grandes frentes, cujo formato final dependerá do embate das idéias e da prática dos próximos planos plurianuais e de seus respectivos orçamentos. Este balanço na sua versão mais ampla está registrado em um Livro Branco sobre o desafio do planejamento governamental. Ele é o resultado de uma análise crítica do trabalho realizado nos últimos oito anos e da consulta a um grupo de atores interessados: autoridades governamentais, empresários, especialistas, políticos e jornalistas.

\section{Planejamento de longo prazo - aprofundar o planejamento de longo prazo, referenciado ao território, à sustentabilidade e à governança}

O PPA 1996-1999 introduziu o conceito de Eixos de Integração e Desenvolvimento como unidade de programação territorial e de empreendimento estruturante. O enfoque espacial inovador dos Eixos de Integração ampliou os horizontes de planejamento, introduzindo a visão estratégica de longo prazo e a identificação dos investimentos públicos e privados, para induzir o desenvolvimento em cada região. As experiências com a implementação e a avaliação do PPA 2000-2003 criaram, por sua vez, o conhecimento e as oportunidades para novos aperfeiçoamentos.

No estágio atual, um dos desafios mais importantes é o de criar mecanismos para articular as políticas setoriais, tendo como referência comum o ordenamento e o desenvolvimento integrado e solidário das regiões, de forma a reduzir disparidades regionais e sociais. O resultado prático é a possibilidade de traduzir as políticas setoriais em um portfolio multissetorial de projetos estruturantes, integrados e sinérgicos, que explicitem a estratégia de desenvolvimento em cada espaço do território nacional.

Essa visão do território nacional, tratada como um todo em busca de coerência e equilíbrio, ganhou nova inspiração com a possibilidade de 
transformá-lo a partir dos princípios da sustentabilidade ampla e da governança, mas há ainda largos passos a dar. No primeiro caso, o planejamento deve levar em conta a combinação ótima da demanda social, econômica, político-institucional e ambiental do desenvolvimento e no segundo, a necessidade de submeter as propostas de governo a processo amplo de negociação com os poderes constituídos, instituições públicas e privadas e segmentos representativos da sociedade civil organizada.

Nos últimos 15 anos, diante dos modelos tradicionais de ordenamento e desenvolvimento do território, emerge outro modelo: o do desenvolvimento local. As suas virtudes estão assentadas no despertar do cidadão que quer ser ator do desenvolvimento, e não mais seu objeto, na estruturação de pequenas e médias empresas locais em torno de um segmento econômico que ganha economias de escala, a partir de sinergias de proximidade. Se, no primeiro caso, as exigências de eqüidade e equilíbrio inter-regional estão demonstradas em vários países que adotaram uma visão integral do território, como é o caso emblemático da França, são inegáveis as vantagens, em termos de eficácia econômica, que o desenvolvimento local aporta, como se depreende de experiências na Itália. Assim, a valorização da gestão do desenvolvimento local, associada à implementação de empreendimentos estruturantes dos Eixos Nacionais de Integração e Desenvolvimento, pode resultar em resposta mais efetiva ao desafio de promover o desenvolvimento sustentável, particularmente em regiões deprimidas. Ao mesmo tempo, o aperfeiçoamento do estudo dos eixos, com a inclusão dos arranjos produtivos locais e das regiões deprimidas, deve enriquecer o leque de oportunidades de investimentos capazes de estimular o desenvolvimento. A gestão do desenvolvimento local é, ainda, um instrumento importante para integrar as ações multissetoriais de Governo Federal e ampliar a participação da comunidade na implementação dessas ações.

A noção de eixos como unidade de programação territorial traz implícita duas ambições metodológicas, nem sempre bem compreendidas ou realizadas com êxito pleno. A primeira está no fato de privilegiar uma visão geoeconômica de desenvolvimento dos territórios sobre a visão geopolítica/administrativa, recortando o espaço brasileiro a partir da sua dinâmica sócio-econômica e ambiental e da interdependência entre as regiões ou Estados. A segunda, fortemente influenciada pela anterior, está em valorizar, na análise do território, os fluxos inter-regionais sobre os fixos, entendidos estes últimos como os ativos que caracterizam cada região. A idéia é que a atratividade de qualquer região depende tanto das suas características em termos sócio-econômicos, ambientais e políticoinstitucionais, como das relações que esta mantém com o seu ambiente externo. Contudo, verifica-se uma insuficiência de informações, estatísticas e estudos que permitam aprofundar esta análise e ampliar os resultados 
em termos de definição de investimentos estruturantes, qualidade e focalização do gasto com vistas a um desenvolvimento harmônico das regiões a um custo menor e mais racional.

\section{Financiamento do Plano Plurianual - ampliar o modelo de financiamento para articular recursos públicos e privados}

O desafio de encontrar formas inovadoras para financiar o desenvolvimento vem adquirindo importância crescente nos últimos anos, em decorrência do agravamento da crise fiscal do setor público. No país e no exterior, estão sendo discutidas e experimentadas novas maneiras de viabilizar a ampliação da oferta de serviços sociais e de infra-estrutura econômica. O fenômeno não é restrito a países em desenvolvimento. Soluções inovadoras nesse campo têm vindo da União Européia, onde as regras de integração ao bloco econômico impõem severas restrições ao gasto público.

A implementabilidade do plano de governo em tais circunstâncias precisa ser discutida mais amplamente com o Legislativo e com a sociedade, visando construir consensos sobre novos mecanismos de financiamento e modelos alternativos de viabilização de investimentos, para ampliar a oferta de serviços de interesse público à sociedade.

Um elemento importante para dar consistência ao Plano Plurianual seria a elaboração de uma estratégia de financiamento, integrada ao plano, que orientasse a modelagem financeira, e para viabilizar a implementação dos programas. O conteúdo dessa estratégia teria natureza indicativa, cuidando de apontar, em linhas gerais, por setor e região, as principais fontes, as parcerias potenciais, os mecanismos de alavancagem financeira e de mitigação de riscos adequados para cada situação específica. Serviria, também, para dar foco ao portfolio das agências federais de crédito e fomento.

Outro requisito essencial nessa trajetória é a internalização, no setor público, do conhecimento necessário à utilização de modernas técnicas de estruturação de parcerias público-privadas. Nesse sentido, poderia ser ampliada para outras áreas de governo a agenda de capacitação e cooperação internacional, que vem sendo desenvolvida no Ministério do Planejamento, para a implantação de uma unidade piloto de parceria público-privada.

Uma outra linha de ação está associada à evolução recente do conceito de serviço de interesse público. Cada vez mais, toma corpo a percepção de que a ação pública não é privilégio exclusivo do Estado. Organizações da sociedade têm demonstrado que podem prestar serviços públicos de relevante interessante social, mobilizando recursos, articulando parcerias e produzindo soluções freqüentemente inovadoras. $\mathrm{O}$ incremento da participação do terceiro setor na implementação de programas do governo é uma alternativa 
consistente para incorporar ao investimento público a capacidade de mobilização e de gestão das organizações não-governamentais.

Uma das contribuições relevantes do estudo dos Eixos Nacionais de Integração e Desenvolvimento ao planejamento público foi organizar as oportunidades de investimento em grupos de projetos sinérgicos, capazes de alavancar o desenvolvimento de um espaço territorial. A implantação integrada desses investimentos potencializa os seus efeitos, além de reduzir custos e prazos de maturação. Substituir, portanto, a prática de financiar projetos isolados, adotando, em seu lugar, a visão de grupos integrados de projetos ou programas de efeito estruturante, seria um passo importante para melhorar o desempenho e otimizar o uso de recursos escassos, tanto no âmbito do governo como no campo de atuação das agências de fomento, nacionais ou internacionais.

Em uma mesma linha de raciocínio, investimentos em arranjos produtivos locais articulados com projetos de infra-estrutura econômica são também uma forma de potencializar resultados, principalmente em regiões deprimidas ou nos espaços de integração continental em fase de implementação.

A estruturação de engenharias financeiras mais apropriadas aos projetos estruturantes do desenvolvimento, com maior oferta de recursos a menores custos, também pode ser aperfeiçoada com a utilização de instrumentos modernos de mitigação de riscos pelas agências multilaterais de financiamento.

Em uma outra perspectiva, deve-se ter presente a necessidade de fortalecimento dos fundos de pensão como fonte de recursos de longo prazo, para o financiamento da infra-estrutura econômica. È também importante o estímulo à criação de fundos de previdência complementar nos Estados e municípios, como forma, em um primeiro momento, de melhorar o fluxo de caixa das unidades da Federação e, em um prazo maior, de gerar recursos adicionais para o financiamento de longo prazo.

\section{Gestão empreendedora - adotar o programa como unidade de gestão}

A introdução da gestão por programas no ambiente atual da administração pública engendra uma tensão entre as práticas existentes e os novos valores e atitudes empreendedoras, características da administração orientada para resultados. A estratégia tem consistido em manejar essa tensão, de tal modo que sua intensidade não seja um obstáculo, mas, ao contrário, exerça um efeito indutor do processo de mudança. Para tanto, é necessário superar progressivamente um certo número de óbices, à medida que avança a implementação do novo modelo integrado de planejamento, orçamento e gestão. 
Não parece haver dúvidas quanto ao progresso que representou a adoção do conceito de programa não só como forma de integrar o PPA e os orçamentos anuais, mas em termos de transparência da alocação dos recursos públicos e de compromisso da gestão com resultados. Contudo, outros passos devem ainda ser dados para que a gestão governamental se direcione efetivamente para transformações na sociedade, em lugar de orientar-se apenas para processos e produtos. Essa mudança depende, em grande medida, do esforço que seja feito para consolidar o programa como unidade de gestão. Depende, igualmente, de uma adaptação das organizações do setor público, de modo a dotá-las de capacidade de gestão matricial e adotar o Estado de gestão multissetorial. Significa, em outros termos, implementar uma reforma de Estado, que combine, simultaneamente, os princípios da Reforma do Aparelho de Estado, de 1995, fortemente voltada para o aumento da produtividade e qualidade, a partir de uma transformação das organizações, e as mudanças introduzidas pelo ciclo de gestão do gasto, que traduz a preocupação, essencial ao Estado moderno, com os impactos na sociedade.

\section{Ajustar as organizações à gestão por programas}

Devem-se criar organizações que conciliem funções e objetivos. A gestão por programa introduz um conflito entre a estrutura departamental e uma atuação por objetivos. Em outras palavras, acentua-se a contradição entre as visões setoriais e o objetivo do programa, que, por definição, é visto sob a perspectiva externa da demanda da sociedade.

Até certa intensidade, esse conflito tem efeitos benéficos, pois contribui para o equilíbrio entre eficácia e eficiência dos resultados da organização. O desafio, nessas circunstâncias, é o de imprimir velocidade ao processo de transformação da organização em seus vários aspectos, a saber: estrutura, valores, liderança, estratégia, desenvolvimento de pessoal e sistemas de informação e controle.

Para tanto, é fundamental, em primeiro lugar, que os objetivos dos programas espelhem com precisão, em cada ministério, os problemas ou as oportunidades que devem ser enfrentados, para viabilizar uma situação futura desejada, compatível com uma orientação estratégica que integre e mobilize a equipe do ministério. Essa orientação, por sua vez, deve refletir os compromissos do governo.

Outro passo importante é o fortalecimento e a integração das funções de planejamento, orçamento e gestão dos ministérios. Em uma perspectiva de gestão por resultados, é recomendável que se dê ênfase ao planejamento e à gestão estratégica, à elaboração e execução orçamentária e financeira orientada pelos resultados dos programas, a um processo contínuo de evolução 
organizacional, que tenha por objetivo incorporar a gestão por programas às estruturas formais e aos processos decisórios da organização.

É desejável, ainda, que todos os eventos do ciclo de gestão do gasto do governo tenham como referência os programas e seus resultados. O objetivo é assegurar que o programa atue como elemento integrador desse processo, ao estabelecer uma linguagem comum para as atividades de elaboração, revisão e avaliação do Plano Plurianual, definição de prioridades e metas na Lei de Diretrizes Orçamentárias, elaboração dos orçamentos, programação orçamentária e financeira, programação plurianual físico-financeira, auditoria interna e externa.

Outro aspecto relevante é a apropriação de custos. Atualmente, os principais gastos administrativos da máquina de governo não estão relacionados aos programas para cujos resultados contribuem. É o caso, principalmente, das despesas de pessoal. A adequada apropriação desses custos, relacionando-os diretamente a resultados, será um avanço importante na forma de proceder à racionalização e à melhoria da qualidade do gasto. Dar-se-á, com isso, transparência aos custos de bens e serviços, evidenciando a relação custo/benefício do programa. Será possível também, e pela primeira vez, introduzir uma gestão de pessoal que tome em conta as necessidades de competências e o número de funcionários, em função de resultados esperados na sociedade, dando aos servidores uma definição clara de sua contribuição para elevar o valor público da administração pública.

A transparência para a sociedade e o fortalecimento do controle social são contribuições importantes do modelo de gestão por programa. Essas conquistas podem ser ampliadas com a utilização mais intensa do programa e de seus resultados como instrumentos de diálogo do governo com a sociedade. O programa, assim, transforma-se no referencial ideal para a discussão pública sobre os resultados atingidos e as melhorias necessárias ao seu aperfeiçoamento contínuo. Permite, ao mesmo tempo, estabelecer uma relação de co-responsabilidade entre a comunidade e o Estado, para assegurar a transformação social, medida crucial em face das dificuldades fiscais e do tamanho dos desafios de um país em desenvolvimento.

\section{Prover informação gerencial}

Tornar disponíveis para a alta direção do governo as informações de desempenho físico e financeiro das ações de cada programa, seus resultados e as restrições que enfrenta durante a execução é condição fundamental para o monitoramento e a coordenação do plano e do orçamento. No primeiro ano do Plano Plurianual 2000-2003, foram atingidos apenas $37 \%$ de ações com capacidade de correlacionar a execução física à financeira. Em 2001, elevou-se este índice para 49\%. É possível chegar ao final 
de 2002 com um nível de controle próximo de 65\%. Para isso há medidas em curso de simplificação e adequação ao uso do sistema de informações gerenciais, de capacitação de pessoal e da auditoria dos programas.

\section{Generalizar a cultura de avaliação de desempenho}

Dar conseqüência à avaliação de desempenho no processo alocativo e na gestão pública. Assim, a avaliação de desempenho voltase para o aperfeiçoamento contínuo do novo modelo de gestão. Assume um papel de transformação da gestão. Tem por base a auto-avaliação dos programas e se desenvolve de modo a constituir um processo de interação de gerentes, equipes, órgãos de supervisão setoriais e de coordenação geral, para a análise crítica dos resultados e das restrições, bem como a pactuação dos aperfeiçoamentos possíveis. O desafio é o da sensibilização e capacitação de gestores, como também o aprendizado de novas metodologias, para a construção coletiva de uma cultura gerencial de avaliação de desempenho que se caracterize pela participação e pela transparência. $\mathrm{O}$ processo desenvolve-se de modo a integrar as organizações responsáveis pelo planejamento, orçamento e gestão e para criar as condições necessárias à implementação dos aperfeiçoamentos.

\section{Dar flexibilidade aos procedimentos administrativos e de execução orçamentária}

Mesmo em um ambiente de ajuste fiscal, que tem prevalecido ao longo do período de implementação do novo modelo de gestão na administração pública brasileira, a falta de recursos financeiros é apenas a segunda mais importante restrição à gestão do plano e dos orçamentos. A maior restrição é a rigidez de procedimentos administrativos e de execução orçamentária, que ainda não incorporam as novas condicionantes da gestão por programas. As dificuldades concentram-se, sobretudo, nos contratos, na rigidez orçamentária e financeira, na descentralização de políticas e nas alterações do plano e do orçamento, motivadas por circunstâncias, por vezes, imprevistas na condução dos programas por alterações feitas obrigatoriamente por meio de projeto de lei.

\section{Estabelecer a comunicação com a sociedade}

A gestão orientada para resultados cria percepções de ganhos e perdas. Perdem as estruturas da organização, cujo poder é aparentemente 
ameaçado pela transparência que decorre da gestão por programas. Ganham os segmentos da sociedade beneficiários dos programas e os gestores de alto nível da administração pública, que são avaliados em função dos resultados percebidos pela sociedade em geral. Nesse contexto, a comunicação com a sociedade assume um papel de melhoria constante dos programas e de transformação da gestão. Nossa experiência tem mostrado que a interação com o público-alvo do programa é um dos principais fatores de motivação dos gerentes e uma referência concreta para sua ação integradora da organização.

Outra vertente da comunicação dirige-se ao Congresso Nacional e aos seus parlamentares, cuja compreensão e adesão ao modelo estimulariam a sua difusão e o incremento mais rápido dos princípios na Administração Pública Federal.

\section{Introduzir parcerias}

A gestão por programas oferece uma visão mais ampla no que concerne à origem e à natureza dos recursos necessários à consecução de objetivos da administração pública. Um programa concebido sob essa nova perspectiva pode articular ações de diferentes agentes públicos ou privados, como também recursos outros que não só financeiros - pessoas, conhecimento, capacidade de gestão e recursos materiais - para a obtenção dos resultados desejados. A experiência tem demonstrado que aqui se encontra a maior fonte de melhoria da qualidade do gasto público. Contudo, tais resultados dependem da transformação mais difícil de ser conquistada: o comportamento empreendedor dos gerentes públicos, inseridos em um ambiente organizacional tradicionalmente burocrático.

\section{Gestão de programas estratégicos}

As experiências recentes com o Brasil em Ação e o Plano Plurianual 2000-2003 demonstraram a utilidade de se intensificar o gerenciamento de ações de elevado conteúdo estratégico. O desafio, nesse caso, é aprimorar o processo de seleção de programas ou projetos estruturantes, que reflitam as prioridades e o compromisso do governo. É recomendável, também, limitar o número e o valor dos programas e projetos estratégicos, de modo a assegurar a continuidade da sua implementação.

\section{Desenvolvimento gerencial ampliar a capacitação gerencial}

Novas habilidades gerenciais necessitam ser reforçadas ou desenvolvidas. A gestão por programas demanda gerentes capazes de integrar esforços de pessoas e equipes dentro e fora da organização à qual foi 
atribuída a condução do programa. Capacidade de negociação, de motivação de equipes próprias ou remotas, comunicação com o públicoalvo do programa, conhecimento das técnicas de gestão de projetos e programas são as habilidades essenciais ao sucesso do novo modelo de gestão. Essas habilidades são demandadas ao extremo, quando o programa tem o caráter multissetorial ou baseia-se em um arranjo de parcerias públicoprivadas. De outra parte, a capacitação gerencial torna-se indispensável em uma administração pública que busca formas de descentralizar e flexibilizar a gestão em nível das equipes que estão próximas do usuário/ beneficiário da ação governamental.

Trata-se, portanto, de elevar a capacidade de resposta não apenas de gerentes de programas e gestores públicos, mas do conjunto de servidores, submetidos a um ambiente de crescente complexidade, e promover uma mudança comportamental, com o objetivo de transformar a atitude burocrática em postura empreendedora. O esforço de capacitação amplo atende, ao mesmo tempo, à necessidade de criar uma linguagem comum de conceitos e procedimentos, essencial a um modelo de gestão em rede. A gestão por programas, diferentemente da gestão departamental, potencializa esse tipo de gerenciamento, à medida que permite organizar as múltiplas áreas de governo e os diversos setores da sociedade em torno de resultados na sociedade, de interesse comum.

\section{Rede de planejamento, orçamento e gestão - aprofundar a integração entre as áreas de planejamento, orçamento e gestão do Governo Federal e sua articulação com Estados e municípios}

O planejamento governamental tende a adotar mecanismos flexíveis de atuação em rede, para articular e coordenar um grande número de agentes, públicos e privados, envolvidos com a oferta de bens e serviços públicos à sociedade, em função da amplitude e diversidade da sua área de abrangência, assim como pela necessidade de adaptação constante a um ambiente em contínua transformação.

A consolidação dessa rede, no Governo Federal, passa pelo revigoramento dos sistemas de planejamento, orçamento e gestão, que compreendem, além dos órgãos centrais, núcleos setoriais distribuídos por toda a Administração Pública Federal. A proposta é que essas estruturas sejam reorganizadas e capacitadas para o exercício de novas funções, assumindo papel mais estratégico na coordenação do planejamento setorial.

A articulação com os Estados e municípios precisa também ser expandida, para aumentar a eficácia e a eficiência das políticas públicas, 
reduzindo sobreposições e potencializando sinergias. O sucesso de qualquer iniciativa nessa direção depende, porém, da modernização dos sistemas de planejamento, orçamento e gestão de Estados e municípios. Para isso, é recomendável esforço concentrado de capacitação, fortalecimento institucional e informatização, com o apoio do Governo Federal.

Não menos importante é o aperfeiçoamento da interface do planejamento com o Congresso Nacional. É preciso ampliar e fortalecer o relacionamento com as assessorias técnicas dos Legislativos e melhorar os fluxos de informações relacionadas ao ciclo de gestão governamental.

Um dos principais entraves à modernização da gestão governamental, entretanto, é a insuficiência quantitativa e qualitativa de informações gerenciais. Por falta de sistemas e métodos adequados, os gerentes nem sempre conseguem obter e consolidar informações sobre os resultados e o desempenho físico dos programas sob sua responsabilidade. Essas dificuldades se multiplicam à medida que ações vão sendo descentralizadas para Estados e municípios.

$\mathrm{Na}$ falta de informações consistentes para subsidiar a decisão, o gerenciamento e a gestão estratégica perdem foco e rapidez. É indispensável, portanto, que o governo prossiga em seus esforços de implementar e integrar sistemas de informações, para apoiar o gerenciamento dos programas, subsidiar a gestão setorial e viabilizar a gestão estratégica do plano. Com isso, seria possível melhorar a qualidade das decisões e, conseqüentemente, o desempenho da gestão pública.

\footnotetext{
Notas

1 Trabalho apresentado no I Encontro Internacional de Gestão Pública, OCDE. Paris, junho 2002. José Paulo Silveira e Ariel Cecílio Garces Pares.
} 


\section{Referências bibliográficas}

O Desafio do Planejamento Governamental. (2002), SPI/MP.

A evolução do Planejamento. (2000), SPI/MP.

Estudo dos Eixos Nacionais de InTEgração e Desenvolvimento. (1999), versão PPA 20002003, BNDES, SPI/MP.

. Versão PPA 2004-2007, em elaboração. 
Resumo

Resumen

Abstract

Revista do

Serviço

Público

\section{Gestão pública orientada para resultados no Brasil}

\section{Ariel Garces e José Paulo Silveira}

O Plano Plurianual (PPA 2000-2003), denominado Avança Brasil, trouxe mudanças de impacto no sistema de planejamento e orçamento federais, assim como na gestão pública.

Após dois anos e meio de implantação desse novo modelo de gestão, é possível contabilizar mudanças importantes e definitivas na administração pública brasileira, tantos quantos são ainda os desafios para a consolidação de uma gestão pública empreendedora. Este texto apresenta os aspectos estruturais desse modelo de gestão pública orientada para resultados, terminando por mencionar os principais desafios que a experiência, apesar de curta, mostra claramente. Estes últimos foram mencionados no Livro Branco do Planejamento Governamental, realizado a partir de uma análise crítica e de uma ampla consulta a atores interessados no tema.

\section{Gestión pública orientada a resultados en Brasil}

\section{Ariel Garces e José Paulo Silveira}

El Plan Plurianual (PPA 2000-2003), llamado Avance Brasil, promovió cambios de impacto en el planeamiento y en el sistema de presupuesto federales, así como en la gestión pública.

Después de dos años y seis meses de implantación de este nuevo modelo de gestión, es posible contabilizar importantes y definitivos cambios en la administración pública brasileña, tantos cuantos son aún los desafíos para consolidación de una gestión pública emprendedora. Este texto presenta los aspectos estructurales de este modelo de gestión pública orientada a resultados, terminando por mencionar los principales desafíos que la experiencia, a pesar de corta, demostra claramente. Estos desafíos fueron mencionados en el Libro Blanco del Planeamiento Gubernamental, llevado a través de un análisis crítico y de una amplia consulta a los atores interesados en el tema.

\section{Results-oriented public management in Brazil \\ Ariel Garces e José Paulo Silveira}

The Pluriannual Plan (PPA 2000-2003), called Advance Brazil, promoted impact changes in the federal planning and budget system, as well as in the public management.

After a two-year-and-a-half implantation of this new management model, it is possible to put into account important and definitive changes in the Brazilian public administration. These changes still are in as much as the challenges to consolidate an entrepreneurial public management. This text presents the structural aspects of this model of results-oriented public management and terminates by mentioning the main challenges that experience, although short, shows clearly. These challenges had been mentioned in The White Book of Governmental Planning, carried through from a critical analysis and an ample consultation to stakeholders.
Ano 53

Número 4

Out-Dez, 2002

Ariel Garces

é diretor de

Planejamento

do Ministério

do Planejamento,

Orçamento e

Gestão.

José Paulo

Silveira é

secretário de

Planejamento,

do Ministério

do Planejamento,

Orçamento e

Gestão.

Contato: ariel.pares@ planejamento.gov.br jose.silveira@ planejamento.gov.br 
